\title{
Consistent condom use increases spontaneous regression in high-risk non-HPV16 but not in HPV16 CIN2-3 lesions, a prospective population-based cohort study
}

Ane Cecilie Munk¹, Irene Tveiterås Øvestad², Einar Gudlaugsson², Kjell Løvslett', Bent Fiane', Bianca van Diermen-Hidle ${ }^{2}$, Arnold-Jan Kruse ${ }^{3}$, Ivar Skaland ${ }^{2}$, Emiel AM Janssen ${ }^{2}$ and Jan PA Baak $k^{2^{*}}$

\begin{abstract}
Background: The major cause of cervical intraepithelial neoplasia (CIN) is persistent infection with human papillomavirus (HPV). Most CIN grade 2 and 3 lesions are treated with cone excision, although a substantial proportion (6-50\%) of CIN2-3 lesions will regresses spontaneously. Predictors for regression of CIN2-3 are desirable in order to reduce this overtreatment.

Methods: In this prospective cohort study, 145 consecutive women with first-time onset CIN2-3 in colposcopy-directed biopsies and standardized biopsy-cone excision interval were included. The genotype of the high-risk human papillomaviruses (=hrHPV) and clinical factors including sexual behaviour, parity, contraception and smoking were assessed. Patients were divided into two groups according to lesions containing HPV16 (hrHPV16+) and high-risk non-HPV16 (hrHPV16-) genotypes.

Results: Women whose partners consistently used condoms showed a significantly higher regression rate than women using other types of contraception ( $53 \%$ versus $13 \%, p<0.0001)$. However, this effect was only seen in hrHPV16- patients (73\% regression rate versus 13\%, $\mathrm{p}<0.0001)$. HrHPV16+ patients had a significantly higher number of sexual partners and more current smokers compared to hrHPV16- patients. The regression rate was not significantly different in CIN2-3 lesions containing HPV16 (hrHPV16+) versus hrHPV16- genotypes.
\end{abstract}

Conclusions: Heterogeneity among hrHPV genotypes excists. HPV-genotype analyses can identify women who significantly increase their chance of regression by consistent condom use.

Keywords: CIN2-3, High-risk HPV, HPV16, Regression, Condom use, Clinical factors

\section{Background}

Cervical intraepithelial neoplasia $(=\mathrm{CIN})$ is the premalignant condition of invasive cervical cancer caused by persistent infection with HPV, which can be detected in over $99 \%$ of high-grade CINs and cervical cancers $[1,2]$. HPV is the most common sexually transmitted agent worldwide [3,4] and up to $80 \%$ of all women will be infected with genital HPV during life [3,5]. Most infections clear within 1-2 years [6,7], but a minority of

\footnotetext{
* Correspondence: jpabaak47@yahoo.com

${ }^{2}$ Department of Pathology, Stavanger University Hospital, Box 8100, 4068 Stavanger, Norway

Full list of author information is available at the end of the article
}

women with high-risk HPV will develop CIN $[8,9]$. CIN lesions are dynamic, which means they can progress to invasive cancer, persist for many years or regress spontaneously $[10,11]$, depending on the balance between the virus and host factors such as the individual local immune response [12,13]. Several risk factors for development of CIN have been identified, including sexual behaviour, parity, contraception type and smoking [6,14-17]. However, there are only a few studies on regression in relation to already established CIN and HPV genotypes [13,18-20].

The standard treatment of punch-biopsy detected high-grade CIN2-3 is cone excision, although only about 
$30 \%$ eventually progress to cancer [21]. A substantial proportion (6-50\%) of CIN 2-3 regress spontaneously over time depending on diagnostic criteria and followup time $[10,11,18]$. Cone excision is an invasive procedure, carrying the risk of potential complications [22]. The most serious complication is cervical insufficiency in a future pregnancy, leading to a higher risk of late abortion and preterm delivery during the second and early third trimester of pregnancy [23,24]. Furthermore, current screening programs and conventional therapeutic guidelines lead to considerable and increasing over-treatment of CIN [25]. Due to the lack of known factors, which could predict or promote regression of CIN 2-3, many women are treated unnecessarily with cone excision, although many would have regressed spontaneously within months $[18,26]$.

Different $h r \mathrm{HPV}$ genotypes have different carcinogenic potential. HPV16 is the most common hrHPV genotype found in more than $50 \%$ of cervical cancers [27]. Further, HPV16 is the most carcinogenic one with the highest risk of CIN2-3 lesions progressing to invasive cancer and a lower probability of regression compared to other genotypes $[13,28,29]$.

The aim of this prospective study was to examine potential associations between $h r H P V$ genotypes, regression rate and clinical factors such as sexual behaviour, parity, condom use and smoking in women with first-time onset CIN2-3 and standardized long interval (median 16 weeks) between punch biopsy and cone excision [18].

\section{Methods}

The study has been approved by the Norwegian Regional Ethical committee (\#NR303.06), the Social and Health Department (\#07/3300) and the Norwegian Social Science Data Service (\#17185). All patients gave written informed consent.

\section{Gynecologic and pathology methods}

Two hundred and fifty-four women aged 25-40 years, who were referred to the gynecology outpatient clinic at Stavanger University Hospital for evaluation of atypical cytological cervical smear between January 2007 and December 2008, were consecutively included. Norwegian guidelines for examination and reporting of atypical cytology were followed: 1 . Low grade Squamous Intraepithelial Lesion (LSIL) or 2. Atypical Squamous Cells of Undetermined Significance (ASCUS) + hrHPV positivity, 3. Recurrences of $h r \mathrm{HPV}$ positive cervical smears, 4. Atypical Squamous Cells, can not rule out a Highgrade lesion (ASC-H) and 5. High Grade Squamous Intraepithelial Lesion (HSIL).

One hundred and nine patients were excluded due to various reasons (Figure 1). Follow-up consisted of at least 3 visits to the gynecology outpatient clinic.
At the $1^{\text {st }}$ visit patient characteristics and clinical data regarding age, number of sexual partners, age at first sexual intercourse, sexual activity span (= interval between first sexual intercourse and age at study inclusion), parity, contraception and smoking were registered. A colposcopy was performed prior to punch biopsies and endo-cervical curettage.

At the $2^{\text {nd }}$ visit (week 7-9) a second colposcopy was performed to detect any fast developing premalignant mucosal changes in the transformation zone.

At the $3^{\text {rd }}$ visit (between 12 and 24 weeks) patients' use of contraceptives since the baseline visit was assessed and interval between biopsy and cone excision calculated. Consistent condom use was defined as those women, whose partners used condoms for all instances of sexual intercourse in the interval between biopsy and cone excision. Finally, after a third colposcopy a cone excision of the abnormal area was performed using a loop electrosurgical excision procedure. Cone excision after more than 16 weeks after punch biopsy was related to patient delay.

According to standard operating procedures punch biopsies and conisation material were fixed in $4 \%$ buffered formaldehyde $(24-48 \mathrm{~h})$ at $20^{\circ} \mathrm{C}$ and embedded in $56{ }^{\circ} \mathrm{C}$ paraffin. All fixed biopsies were carefully oriented by using Eosin-mediated embedding, which allows macroscopic identification of the epithelium and reduces erroneous orientation of the biopsy in the paraffin block and thereby tangential cutting.

The Norwegian national guidelines for histological grading of cervical dysplasia recommend to follow the CIN classification which classify low-grade dysplasia or cervical intraepithelial neoplasia grade 1 (CIN1) as equivalent to cytological LSIL. Moderate-dysplasia or CIN2 and severe dysplasia/carcinoma in situ or CIN3 as equivalent to cytological HSIL [30]. The diagnosis of each CIN grade is based on well-defined histopathological criteria [31]. Standard Hematoxylin Erythrosin Saffran (HES) sections were used for histological evaluation and independently reviewed by two experienced gynecological pathologists (EG, JB), who were blinded for each other's diagnosis. The proliferation marker Ki67 and the tumour suppressor protein p16 were used to optimize the diagnoses [13,32]. Regression was defined as a CIN2-3 diagnosis in the cervical biopsy and CIN1 or less in the subsequent cone.

\section{HPV- analysis}

DNA- material from all biopsies at inclusion was isolated (E.Z.N.A. ${ }^{\text {TM }}$ Tissue DNA Kit, Omega Bio-Tek, Inc., Norcross, GA, USA). HPV analyses were performed using Linear Array (LA) HPV Genotyping test (Roche Molecular Systems, Roche Diagnostics, Mannheim, Germany), which detects 37 different HPV genotypes. 


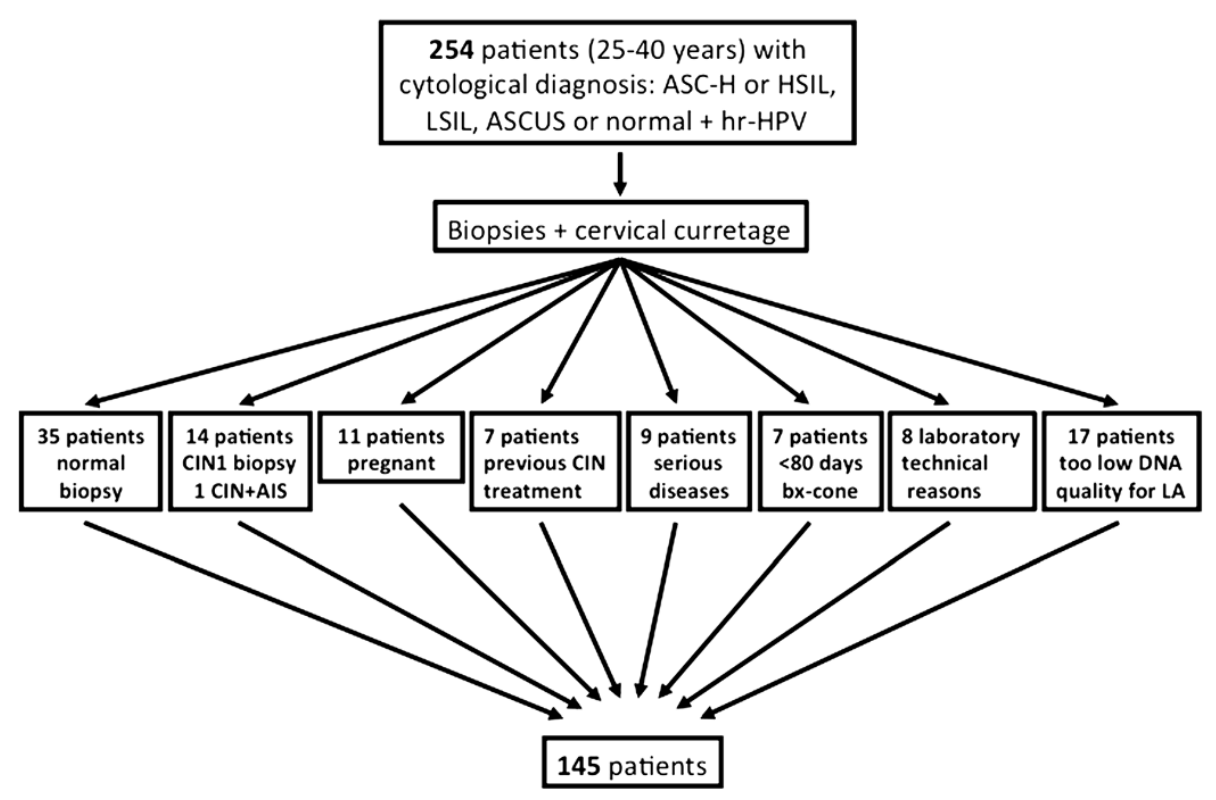

Figure 1 Inclusion and exclusion criteria. Norwegian guidelines for histological examination of atypical cytology were followed: 1. Low grade Squamous Intraepithelial Lesion (LSIL) + high-risk Human Papillomavirus (hr-HPV) or 2. Atypical Squamous Cells of Undetermined Significance (ASCUS) + hr-HPV or 3. Recurrences of hr-HPV positive cervical smears or 4. Atypical Squamous Cells, cannot rule out a High Grade lesion (ASC-H) or 5. High Grade Squamous Intrepithelial Lesion (HSIL). AIS denotes Adenocarcinoma in situ and Bx Biopsy.

The LA primers amplify HPV-DNA from 16 high-risk $(16,18,31,33,35,39,45,51,52,56,58,59,68,73,82$ and IS39, which is a subtype of 82), 3 possible high-risk (26, 53 and 66), 9 unclassified $(55,62,64,67,69,71,83$, 84 and 89) and 9 low-risk genotypes (6, 11, 40, 42, 54, $61,70,72$ and 81 ) in addition to $\beta$-globin DNA as a cellular control. The amplification step was performed according to the Roche users' manual as previously described [13]. Two observers, using the Linear Array HPV Genotyping Test Reference Guide, manually interpreted the LA HPV genotyping strips [13]. All HPV genotyping was done after the diagnostic part of the study and had no influence on the follow up of the patients.

Patients were divided into two groups according to the presence or absence of HPV16. The hrHPV16+ group was positive for HPV16 genotype independent of other genotypes, while the hrHPV16- group was negative for HPV16 but positive for other high-risk genotypes.

\section{Statistical analysis}

SPSS, version 19 (SPSS Inc., Chicago, IL, USA) was used for statistical analyses. Data are presented as median with range unless otherwise stated. The KolmogorovSmirnov test and visual inspection of plots were used to test for normal distribution. Continuous data were analysed by 2-sided t-test or Mann-Whitney U-test, as appropriate.

Receiver operating curve (ROC) analysis (MedCalc Software, Mariakerke, Belgium) was used to calculate cut-off values of the clinical factors: age at inclusion, interval between biopsy and cone excision, age at first sexual intercourse, number of lifetime partners and sexual activity span according to regression versus nonregression [33]. Chi-Square tests were performed to compare categorical variables.

A binary logistic multivariate regression model was applied to perform multivariate analyses. Probabilities $<0.05$ were considered as statistically significant.

\section{Results}

The study population consisted of 145 women with a first-time onset atypical cytological smear and histologically proven CIN2-3. All patients were positive for highrisk or possible high-risk HPV in the punch biopsy (Table 1). No patient was lost to follow-up.

Genotyping revealed that 54 patients were $h r \mathrm{HPV} 16+$ and 91 patients $h r H P V 16-$. The overall regression rate in the study was $18 \%$. The regression rate in the $h r$ HPV16group (20\%) was higher compared to the hrHPV16+ group (15\%), but the difference was not statistically significant. In an additional analysis comparing regression versus non-regression in single and multiple hrHPV-genotypes infected lesions, the regression rates were $22 \%$ and $11 \%$, respectively, a none-significant difference $(\mathrm{p}=0.10)$.

When comparing the two groups in a univariate analysis, $h r H P V 16+$ patients had a significantly higher number of sexual partners and more current smokers 


\begin{tabular}{|c|c|}
\hline HPV genotype & $\begin{array}{l}\text { Number of patients with } \\
\text { one/multiple genotypes }\end{array}$ \\
\hline 16 & $32 / 22$ \\
\hline 18 & $6 / 4$ \\
\hline 31 & $12 / 8$ \\
\hline 33 & $9 / 4$ \\
\hline 35 & $4 / 4$ \\
\hline 39 & $0 / 5$ \\
\hline 45 & $3 / 1$ \\
\hline 51 & $2 / 1$ \\
\hline 52 & $7 / 0$ \\
\hline 58 & $4 / 0$ \\
\hline $26,53,56,59,66,68,73,82$ & $11 / 6$ \\
\hline
\end{tabular}

compared to $h r$ HPV16- patients (Table 2). In a multivariate analysis both numbers of sexual partners and smoking remained statistically different between groups ( $\mathrm{p}=0.006$ and $\mathrm{p}=0.03$, respectively). Age, interval between biopsy and cone excision, distribution of CIN2 and CIN3, parity, age at first sexual intercourse, sexual activity span and condom use were not significantly different between the two hrHPV groups.

Among all women whose partners used condoms for all instances they had intercourse between biopsy and cone excision (= consistent condom use), the regression rate was significantly higher compared to women using other types of contraception or whose partners inconsistently used condoms (9/17, 53\% versus $17 / 128,13 \%)$. However, although consistent condom use was associated with a significantly higher regression rate in the $h r H V P 16$ - group (73\% versus $13 \%$ ), this effect was not seen in $h r$ HPV $16+$ patients (regression rate $16 \%$ versus 15\%). Clinicopathologic features between the 17 consistent condom users and other patients did not differ significantly.

In $h r$ HPV16- patients, age $\leq 15$ years at first sexual intercourse, was associated with a significantly lower regression rate $(4 \%)$ compared to patients with a sexual debut $>15$ years $(25 \%)$ (Table 3). However, in a multivariate analysis only consistent condom use remained as a significant predictor for regression with an odds ratio of 19 (95\% C.I. 4-82, $\mathrm{p}<0.0001)$. Other factors such as age, interval between biopsy and cone excision, single or multiple $h r \mathrm{HPV}$ infections, number of sexual partners, sexual activity span, parity and smoking did not significantly affect regression rate in the hrHVP16group (Table 3). In the hrHPV16+ group none of the examined factors was significantly correlated to regression (Table 4).

\section{Discussion}

This prospective study examined the influence of $h r \mathrm{HPV}$ genotypes on the regression rate. Further, potential interactions of $h r \mathrm{HPV}$ genotypes and clinical factors like age, interval between biopsy and cone excision, single or multiple $h r \mathrm{HPV}$ infections, number of sexual partners, age at first sexual intercourse, sexual activity span, parity, consistent condom use and smoking were evaluated.

The main finding was that consistent condom use significantly increased the regression rate in HPV16-, but not in hrHPV16+ lesions. Further, the number of sexual partners was higher and current smoking was more prevalent in hrHPV16+ than in hrHPV16- patients, with both differences reaching statistical significance both in univariate (Table 2) and multivariate analyses.

In the study population as a whole only consistent condom use was significantly associated with higher regression rates. However, the regression rate overall was not significantly different between $h r H P V 16+$ and hrHPV16- patients.

HPV16 has been described as the genotype with the highest carcinogenic potential, the highest risk for progression to CIN3 and cervical cancer and the highest attribution to cervical cancer worldwide [29,34-36]. HPV16 infections also tend to last longer than infections caused by other $h r \mathrm{HPV}$ types [6]. However, the current study did not find a significantly lower regression rate in $h r$ HPV16+ versus hrHPV16- patients, which is in line with previously published data $[18,20,37]$. There was a relatively small (5\%) difference in regression rate between the two $h r \mathrm{HPV}$-genotype groups investigated in the current study. Based on a retrospective sample size calculation a study of 906 patients per group would be needed to detect this difference with a power of $80 \%$.

A higher number of sexual partners in hrHPV16+ women has also been stated in other studies [19,38]. This could be explained by the fact that increased sexual contact with new partners increases the risk of being infected with HPV16 compared to other $h r$ HPV genotypes, as HPV16 is the most frequent genotype [35]. A significant association between lower age at sexual debut and lower regression rate was found in hrHPV16patients only.

Smoking is counted as a risk factor for CIN development $[6,17,39]$, but data on the effect of smoking in relation to HPV genotype are sparse. Previous studies have shown that cotinine and nicotine metabolites, which potentially have mutagenous effects on the cervical epithelium, accumulate in the cervical mucus of active cigarette smokers [40,41]. As current smoking was more prevalent among hrHPV16+ patients, smoking could potentiate the mutagenic effects of $h r H P V 16$ resulting in an increased risk of developing CIN. Another potential explanation for the higher prevalence of smokers among 
Table 2 Clinical variables in hrHPV16 + versus hrHPV16- patients

\begin{tabular}{|c|c|c|c|c|}
\hline Variables & $\begin{array}{l}\text { Number } \\
n=145(\%)\end{array}$ & $\begin{array}{l}\text { HPV16+ } \\
\mathrm{n}=54(\%)\end{array}$ & $\begin{array}{l}\text { HPV16- } \\
\quad n=91 \text { (\%) }\end{array}$ & p-value \\
\hline Regression & $26(18)$ & $8(15)$ & $18(20)$ & 0.5 \\
\hline Non-regression & $119(82)$ & $46(85)$ & $73(80)$ & \\
\hline \multicolumn{5}{|l|}{ Age } \\
\hline (median, min.-max., years) & $31(25-41)$ & $32(25-41)$ & $30(25-41)$ & 1.0 \\
\hline$\leq 30$ & $66(45)$ & $20(37)$ & $46(51)$ & 0.1 \\
\hline$>30$ & $79(55)$ & $34(63)$ & $45(49)$ & \\
\hline \multicolumn{5}{|l|}{ Interval biopsy-cone } \\
\hline (median, min.-max., days) & $113(84-171)$ & 107(84-154) & $113(84-171)$ & 0.6 \\
\hline$\leq 115$ & $101(70)$ & $38(70)$ & $63(69)$ & 0.9 \\
\hline$>115$ & $44(30)$ & $16(30)$ & $28(31)$ & \\
\hline \multicolumn{5}{|l|}{ CIN diagnosis } \\
\hline $\mathrm{CIN} 2$ & $26(18)$ & $7(13)$ & $19(21)$ & 0.2 \\
\hline CIN3 & $119(82)$ & $47(87)$ & $72(79)$ & \\
\hline \multicolumn{5}{|l|}{ HPV genotype } \\
\hline Single & $91(63)$ & $32(60)$ & $59(65)$ & 0.5 \\
\hline Multiple & $54(37)$ & $22(40)$ & $32(35)$ & \\
\hline \multicolumn{5}{|l|}{ Smoking } \\
\hline Yes & $48(33)$ & $25(46)$ & $23(25)$ & 0.009 \\
\hline No & $97(67)$ & $29(54)$ & $68(75)$ & \\
\hline \multicolumn{5}{|l|}{ Number of sexual partners } \\
\hline $1-9$ & $67(46)$ & $16(30)$ & $51(56)$ & 0.002 \\
\hline$>10$ & $78(54)$ & $38(70)$ & $40(44)$ & \\
\hline \multicolumn{5}{|l|}{ Parity } \\
\hline Yes & $92(63)$ & $36(67)$ & $56(62)$ & 0.5 \\
\hline No & $53(37)$ & $18(33)$ & $35(38)$ & \\
\hline \multicolumn{5}{|c|}{ Age of first sexual intercourse } \\
\hline$\leq 15$ & $38(26)$ & $15(28)$ & $23(25)$ & 0.7 \\
\hline$>15$ & $107(74)$ & $39(72)$ & $68(75)$ & \\
\hline \multicolumn{5}{|l|}{ Sexual activity span } \\
\hline$\leq 13$ & $64(44)$ & $21(39)$ & $43(47)$ & 0.3 \\
\hline$>13$ & $81(56)$ & $33(61)$ & $48(53)$ & \\
\hline \multicolumn{5}{|l|}{ Condom use } \\
\hline Yes & $17(12)$ & $6(11)$ & $11(12)$ & 0.9 \\
\hline No & $128(88)$ & $48(89)$ & $80(88)$ & \\
\hline
\end{tabular}

${ }^{1}$ min.-max.: minimum, maximum.

hrHPV16+ patients is the association of smoking as a lifestyle combined with a higher-risk sexual behavior [42]. Both more sexual partners and smokers among $h r$ HPV16+ patients could indicate that these risk factors are related to lifestyle.

Data indicate that condom use can have a positive effect on CIN regression [33,37]. Condom use reduces the repeated exposure of the cervical mucosa to HPV and the directly immunosuppressive effect of semen on the cervical epithelium. These factors strengthen the local immune system against the HPV infection and may promote CIN regression [43,44]. Another interesting hypothesis is that the latex of the condoms stimulates a general immune response, which might be beneficial in the clearance of HPV.

In hrHPV16- patients consistent condom use increased the regression rate significantly compared to none condom users. Additionally, age $>15$ years at first sexual intercourse was associated with a significantly higher likelihood of regression. None of the examined clinical factors had any significant effect on the regression rate in $h r H P V 16+$ patients. This underlines the heterogeneity among $h r \mathrm{HPV}$ genotypes and that $h r \mathrm{HPV} 16+\mathrm{CIN}$ lesions may behave differently compared to other $h r \mathrm{HPV}$ 
Table 3 Clinical variables in hrHPV16- patients and regression versus non-regression

\begin{tabular}{|c|c|c|c|c|}
\hline Variable & $\begin{array}{l}\text { Number } \\
n=91(\%)\end{array}$ & $\begin{array}{l}\text { Regression } \\
\mathrm{n}=18(\%)\end{array}$ & $\begin{array}{l}\text { Non-regression } \\
\mathrm{n}=73(\%)\end{array}$ & p-value \\
\hline \multicolumn{5}{|l|}{ Age } \\
\hline (median, min.-max., years) & $30(25-41)$ & $29(25-41)$ & $30(25-41)$ & 0.8 \\
\hline$\leq 30$ & $46(50)$ & $10(22)$ & $36(78)$ & 0.6 \\
\hline$>30$ & $45(50)$ & $8(18)$ & $37(82)$ & \\
\hline \multicolumn{5}{|l|}{ Interval biopsy-cone } \\
\hline (median, min.-max., days) & $113(84-171)$ & $108(84-127)$ & $113(84-171)$ & 0.1 \\
\hline$\leq 115$ & $63(69)$ & $14(22)$ & $49(78)$ & 0.4 \\
\hline$>115$ & $28(31)$ & $4(14)$ & $24(86)$ & \\
\hline \multicolumn{5}{|l|}{ CIN diagnosis } \\
\hline CIN2 & $19(21)$ & $5(26)$ & $14(74)$ & 0.4 \\
\hline CIN3 & $72(79)$ & $13(18)$ & $59(82)$ & \\
\hline \multicolumn{5}{|l|}{ HPV genotype } \\
\hline Single & $59(65)$ & $13(22)$ & $46(78)$ & 0.5 \\
\hline Multiple & $32(35)$ & $5(16)$ & $27(84)$ & \\
\hline \multicolumn{5}{|l|}{ Smoking } \\
\hline Yes & $23(25)$ & $2(9)$ & $21(91)$ & 0.1 \\
\hline No & $68(75)$ & $16(24)$ & $52(76)$ & \\
\hline \multicolumn{5}{|c|}{ Number of sexual partners } \\
\hline $1-9$ & $51(56)$ & $11(22)$ & $40(78)$ & 0.6 \\
\hline$>10$ & $40(44)$ & $7(18)$ & $33(82)$ & \\
\hline \multicolumn{5}{|l|}{ Parity } \\
\hline Yes & $56(62)$ & $10(18)$ & $46(82)$ & 0.6 \\
\hline No & $35(39)$ & $8(23)$ & $27(77)$ & \\
\hline \multicolumn{5}{|c|}{ Age of first sexual intercourse } \\
\hline$\leq 15$ & $23(25)$ & $1(4)$ & $22(96)$ & 0.03 \\
\hline$>15$ & $68(75)$ & $17(25)$ & $51(75)$ & \\
\hline \multicolumn{5}{|l|}{ Sexual activity span } \\
\hline$\leq 13$ & $43(47)$ & $11(26)$ & $32(74)$ & 0.2 \\
\hline$>13$ & $48(53)$ & $7(15)$ & $41(85)$ & \\
\hline \multicolumn{5}{|l|}{ Condom use } \\
\hline Yes & $11(12)$ & $8(73)$ & $3(27)$ & $<0.0001$ \\
\hline No & $80(88)$ & $10(13)$ & $70(87)$ & \\
\hline
\end{tabular}

genotypes. HrHPV16+ lesions seem to be less susceptible to cofactors related to sexual behavior and consistent condom use.

Heterogeneity of high-grade CIN related to HPV16 has previously been described in a study by Wentzensen et al., which showed that hrHPV16+ lesions were associated with lower mean age, worse colposcopic appearance and a higher number of lifetime sexual partners compared to hrHPV16- lesions [19].

As consistent condom use does not seem to affect regression rate of $h r \mathrm{HPV} 16+\mathrm{CIN}$ lesions in contrast to hrHPV16- lesions, the behaviour and character of HPV16 and the subsequent immune reaction could be different compared to non-HPV16 high-risk genotypes.
Recent studies have shown interesting results comparing epithelial and immune biomarkers in HPV16+ lesions versus HPV16- CIN2-3 lesions in relation to regression or not $[13,20,45]$.

A better understanding of the different behaviour of HPV genotypes could contribute to a more individualized follow-up and treatment of CIN2-3 patients than today's standard treatment with cone excision of all CIN2-3 lesions.

Consistent use of condoms by the male partners of the women as contraception was rather infrequent. However, the current results showing that consistent condom use by sexual intercourse increases the chances for regression significantly with an odds ratio of 19 in 
Table 4 Clinical variables in hrHPV16+ patients and regression versus non-regression

\begin{tabular}{|c|c|c|c|c|}
\hline Variable & $\begin{array}{l}\text { Number } \\
n=54(\%)\end{array}$ & $\begin{array}{l}\text { Regression } \\
\mathrm{n}=\mathbf{8}(\%)\end{array}$ & $\begin{array}{l}\text { Non-regression } \\
n=46(\%)\end{array}$ & p-value \\
\hline \multicolumn{5}{|l|}{ Age } \\
\hline (median, min-max, years) & $31(25-41)$ & $31(25-41)$ & $31(25-41)$ & 0.9 \\
\hline$\leq 30$ & $20(37)$ & $1(5)$ & $19(95)$ & 0.1 \\
\hline$>30$ & $34(63)$ & $7(20)$ & $27(80)$ & \\
\hline \multicolumn{5}{|l|}{ Interval biopsy-cone } \\
\hline (median, min-max, days) & $113(84-171)$ & $107(84-154)$ & $113(84-171)$ & 0.1 \\
\hline$\leq 115$ & $38(70)$ & $6(16)$ & $32(84)$ & 0.7 \\
\hline$>115$ & $16(30)$ & $2(12)$ & $14(88)$ & \\
\hline \multicolumn{5}{|l|}{ CIN diagnosis } \\
\hline $\mathrm{CIN2}$ & $7(13)$ & $2(29)$ & $5(71)$ & 0.3 \\
\hline CIN3 & $47(87)$ & $6(13)$ & $41(87)$ & \\
\hline \multicolumn{5}{|l|}{ HPV genotype } \\
\hline Single & $32(59)$ & $7(22)$ & $25(78)$ & 0.08 \\
\hline Multiple & $22(41)$ & $1(5)$ & $21(95)$ & \\
\hline \multicolumn{5}{|l|}{ Smoking } \\
\hline Yes & $25(46)$ & $5(20)$ & $20(80)$ & 0.3 \\
\hline No & $29(54)$ & $3(10)$ & $26(90)$ & \\
\hline \multicolumn{5}{|c|}{ Number of sexual partners } \\
\hline $1-9$ & $16(30)$ & $1(6)$ & $15(94)$ & 0.3 \\
\hline$>10$ & $38(70)$ & $7(18)$ & $31(82)$ & \\
\hline \multicolumn{5}{|l|}{ Parity } \\
\hline Yes & $36(67)$ & $6(17)$ & $30(83)$ & 0.6 \\
\hline No & $18(33)$ & $2(11)$ & $16(89)$ & \\
\hline \multicolumn{5}{|c|}{ Age of first sexual intercourse } \\
\hline$\leq 15$ & $15(28)$ & $2(13)$ & $13(87)$ & 0.8 \\
\hline$>15$ & $39(72)$ & $6(15)$ & $33(85)$ & \\
\hline \multicolumn{5}{|l|}{ Sexual activity span } \\
\hline$\leq 13$ & $21(39)$ & $1(5)$ & $20(95)$ & 0.1 \\
\hline$>13$ & $33(61)$ & $7(21)$ & $26(79)$ & \\
\hline \multicolumn{5}{|l|}{ Condom use } \\
\hline Yes & $6(11)$ & $1(16)$ & $5(83)$ & 0.9 \\
\hline No & $48(89)$ & $7(15)$ & $41(85)$ & \\
\hline
\end{tabular}

hrHPV16- lesions, could motivate a substantial proportion of women and their partners to use condoms for a limited time period.

The strength of the current study is the prospective design and the histological definition of CIN regression. The study population was relatively homogenous due to the inclusion criterion of age between 25 and 40 and the standardized interval between biopsy and cone excision. Additionally, both CIN2/CIN3 and consistent condom use was equally distributed across the two HPV groups. All 145 patients had $h r H P V$ positive DNA in the punch biopsies by LA. This strengthens the diagnosis of the current biopsies, and ensures the genotype of the actual
HPV infection. Stavanger University Hospital is the only hospital in the region, making this a population-based cohort study with low selection bias.

The observational period of the study, however, was relatively short in relation to the natural history of CIN. On the other hand, a longer observational period of high-grade CIN regression with the risk of progression could not have been justified at the start of the study. With current data new trials with a longer interval between punch biopsy and cone excision are acceptable in women under 40 years of age with a first time onset CIN2-3 lesion. Further, the sample size is rather moderate, which limits the separate interpretation of clinical factors in each group. 


\section{Conclusions}

In conclusion, consistent condom use significantly increased the regression rate in $h r \mathrm{HPV} 16$ - but not in $h r \mathrm{HPV} 16+$ lesions. This suggests different immunologic response, and might have clinical impact, as HPV genotyping can identify patients who would significantly benefit from consistent condom use. Further heterogeneity is expressed by a higher number of sexual partners and more current smokers in hrHPV16+ patients.

\begin{abstract}
Abbreviations
ASC-H: Atypical Squamous Cells: cannot rule out a High-grade lesion; ASCUS: Atypical Squamous Cells of Undetermined Significance; CIN: Cervical Intraepithelial Neoplasia; HES: Hematoxylin Eosin Safran; HPV: Human Papillomavirus; hr-HPV: high-risk Human Papillomavirus; HSIL: High Grade Squamous Intraepithelial Lesion; LSIL: Low grade Squamous Intraepithelial Lesion; ROC: Receiver Operating Curve.
\end{abstract}

\section{Competing interests}

The authors declare that they have no competing interests.

\section{Authors' contributions}

ACM: Involved in the conception and design of the study, performed inclusion, follow-up and collection of clinical data on the study patients, involved in the data analyses, performed writing of the manuscript. IT Performed the HPV genotyping, involved in the data analyses and interpretation, provided critical revisions of the manuscript. EG: Involved in the conception and design of the study, responsible for all the histological diagnoses. KL: Involved in the conception and design of the study, contributed to clinical supervision concerning the study patients. BF: Involved in the conception and design of the study, contributed to clinical supervision concerning the study patients, provided critical revisions of the manuscript. BDH: Involved in the conception and design of the study, involved in database set-up, performed HPV genotyping. AJK: Involved in the conception and design of the study, provided critical revisions of the manuscript. IS: Involved in the conception and design of the study, responsible for all the immunohistochemical stainings, provided critical revisions of the manuscript. EAJ: Involved in the conception and design of the study, involved in the data analyses, substitution in writing the manuscript and critical revisions of the manuscript. JPB: Principal investigator, involved in the conception and design of the study, reviewed the histological diagnoses, involved in the data analyses, substitution in writing the manuscript and final approval of manuscript. All authors read and approved the final manuscript.

\section{Acknowledgements}

Supported by grants from Helse Vest (Grant number: 911634) and Stavanger University Hospital (Project number: 623102). The authors would also like to thank Marit Nordhus and Anita Hodnefjell for technical laboratory support, and the nurses at the gynecologic outpatient clinic for the assistance with gynecological examination of the study patients.

\section{Author details}

'Department of Obstetrics and Gynecology, Stavanger University Hospital, Stavanger, Norway. ${ }^{2}$ Department of Pathology, Stavanger University Hospital, Box 8100, 4068 Stavanger, Norway. ${ }^{3}$ Department of Gynecology, Academic Hospital Maastricht, Maastricht, The Netherlands.

Received: 30 August 2012 Accepted: 31 October 2012 Published: 5 November 2012

\section{References}

1. Coutlee F, Ratnam S, Ramanakumar AV, Insinga RR, Bentley J, Escott N, Ghatage P, Koushik A, Ferenczy A, Franco EL: Distribution of human papillomavirus genotypes in cervical intraepithelial neoplasia and invasive cervical cancer in Canada. J Med Virol 2011, 83(6):1034-1041.

2. Walboomers JM, Jacobs MV, Manos MM, Bosch FX, Kummer JA, Shah KV, Snijders PJ, Peto J, Meijer CJ, Munoz N: Human papillomavirus is a necessary cause of invasive cervical cancer worldwide. J Pathol 1999, 189(1):12-19.

3. Bosch FX, de Sanjose S: Chapter 1: Human papillomavirus and cervical cancer-burden and assessment of causality. J Natl Cancer Inst Monogr 2003, 31:3-13

4. Aral SO, Adimora AA, Fenton KA: Understanding and responding to disparities in HIV and other sexually transmitted infections in African Americans. Lancet 2008, 372(9635):337-340.

5. Syrjanen K, Hakama M, Saarikoski S, Vayrynen M, Yliskoski M, Syrjanen S, Kataja V, Castren O: Prevalence, incidence, and estimated life-time risk of cervical human papillomavirus infections in a nonselected Finnish female population. Sex Transm Dis 1990, 17(1):15-19.

6. Ho GY, Bierman R, Beardsley L, Chang CJ, Burk RD: Natural history of cervicovaginal papillomavirus infection in young women. $N$ Engl J Med 1998, 338(7):423-428.

7. Woodman CB, Collins S, Winter H, Bailey A, Ellis J, Prior P, Yates M, Rollason TP, Young LS: Natural history of cervical human papillomavirus infection in young women: a longitudinal cohort study. Lancet 2001, 357(9271):1831-1836.

8. Koutsky LA, Holmes KK, Critchlow CW, Stevens CE, Paavonen J, Beckmann AM, DeRouen TA, Galloway DA, Vernon D, Kiviat NB: A cohort study of the risk of cervical intraepithelial neoplasia grade 2 or 3 in relation to papillomavirus infection. N Engl J Med 1992, 327(18):1272-1278

9. Rozendaal L, Westerga J, van der Linden JC, Walboomers JM, Voorhorst FJ, Risse EK, Boon ME, Meijer CJ: PCR based high risk HPV testing is superior to neural network based screening for predicting incident CIN III in women with normal cytology and borderline changes. J Clin Pathol 2000, 53(8):606-611.

10. Ostor AG: Natural history of cervical intraepithelial neoplasia: a critical review. Int J Gynecol Pathol 1993, 12(2):186-192.

11. Nasiell K, Nasiell M, Vaclavinkova V: Behavior of moderate cervical dysplasia during long-term follow-up. Obstet Gynecol 1983, 61(5):609-614

12. Baak JP, Kruse AJ, Robboy SJ, Janssen EA, van Diermen B, Skaland I: Dynamic behavioural interpretation of cervical intraepithelial neoplasia with molecular biomarkers. J Clin Pathol 2006, 59(10):1017-1028.

13. Ovestad IT, Gudlaugsson E, Skaland I, Malpica A, Kruse AJ, Janssen EA, Baak JP: Local immune response in the microenvironment of CIN2-3 with and without spontaneous regression. Modern pathology: an official journal of the United States and Canadian Academy of Pathology, Inc 2010, 23(9):1231-1240.

14. International Collaboration of Epidemiological Studies of Cervical Cancer: Cervical carcinoma and sexual behavior: collaborative reanalysis of individual data on 15,461 women with cervical carcinoma and 29,164 women without cervical carcinoma from 21 epidemiological studies. Cancer epidemiology, biomarkers \& prevention: a publication of the American Association for Cancer Research, cosponsored by the American Society of Preventive Oncology 2009, 18(4):1060-1069.

15. Munoz N, Franceschi S, Bosetti C, Moreno V, Herrero R, Smith JS, Shah KV, Meijer CJ, Bosch FX: Role of parity and human papillomavirus in cervical cancer: the IARC multicentric case-control study. Lancet 2002, 359(9312):1093-1101.

16. Smith JS, Green J, Berrington de Gonzalez A, Appleby P, Plummer M, Beral V: Cervical cancer and use of hormonal contraceptives: a systematic review. Lancet 2003, 361(9364):1159-1167.

17. Trimble CL, Genkinger JM, Burke AE, Hoffman SC, Helzlsouer KJ, Diener-West M, Comstock GW, Alberg AJ: Active and passive cigarette smoking and the risk of cervical neoplasia. Obstet Gynecol 2005, 105(1):174-181.

18. Trimble CL, Piantadosi S, Gravitt P, Ronnett B, Pizer E, Elko A, Wilgus B, Yutzy W, Daniel R, Shah K, et al: Spontaneous regression of high-grade cervical dysplasia: effects of human papillomavirus type and HLA phenotype. Clinical cancer research: an official journal of the American Association for Cancer Research 2005, 11(13):4717-4723.

19. Wentzensen N, Walker J, Schiffman M, Yang HP, Zuna RE, Dunn ST, Allen RA, Zhang R, Sherman M, Gold MA, Wang SS: Heterogeneity of high grade cervical intraepithelial neoplasia related to HPV16: Implications for natural history and management. Int J Cancer 2013 Jan 1, 132(1):148-154.

20. Baak JP, Kruse AJ, Garland SM, Skaland I, Janssen EA, Tabrizi S, Fagerheim S, Robboy S, Nilsen ST: Combined p53 and retinoblastoma protein 
detection identifies persistent and regressive cervical high-grade squamous intraepithelial lesions. Am J Surg Pathol 2005, 29(8):1062-1066.

21. McCredie MR, Sharples K, Paul C, Baranyai J, Medley G, Jones RW, Skegg DC: Natural history of cervical neoplasia and risk of invasive cancer in women with cervical intraepithelial neoplasia 3: a retrospective cohort study. The lancet oncology 2008, 9(5):425-434.

22. Hagen B, Skjeldestad FE, Bratt H, Tingulstad S, Lie AK: CO2 laser conization for cervical intraepithelial neoplasia grade II-III: complications and efficacy. Acta Obstet Gynecol Scand 1998, 77(5):558-563.

23. Kyrgiou M, Koliopoulos G, Martin-Hirsch P, Arbyn M, Prendiville W, Paraskevaidis E: Obstetric outcomes after conservative treatment for intraepithelial or early invasive cervical lesions: systematic review and meta-analysis. Lancet 2006, 367(9509):489-498.

24. Albrechtsen S, Rasmussen S, Thoresen S, Irgens LM, Iversen OE: Pregnancy outcome in women before and after cervical conisation: population based cohort study. BMJ 2008, 337:a1343.

25. Barken SS, Rebolj M, Andersen ES, Lynge E: Frequency of cervical intraepithelial neoplasia treatment in a well-screened population. Int J Cancer 2012, 130(10):2438-2444.

26. Munk AC, Kruse AJ, van Diermen B, Janssen EA, Skaland I, Gudlaugsson E, Nilsen ST, Baak JP: Cervical intraepithelial neoplasia grade 3 lesions can regress. APMIS: acta pathologica, microbiologica, et immunologica Scandinavica 2007, 115(12):1409-1414.

27. Munoz N, Bosch FX, de Sanjose S, Herrero R, Castellsague X, Shah KV, Snijders PJ, Meijer CJ: Epidemiologic classification of human papillomavirus types associated with cervical cancer. N Engl J Med 2003, 348(6):518-527.

28. Cogliano V, Baan R, Straif K, Grosse Y, Secretan B, El Ghissassi F: Carcinogenicity of human papillomaviruses. Lancet Oncol 2005, 6(4):204.

29. Kjaer SK, Frederiksen K, Munk C, Iftner T: Long-term absolute risk of cervical intraepithelial neoplasia grade 3 or worse following human papillomavirus infection: role of persistence. J Natl Cancer Inst 2010, 102(19):1478-1488.

30. Steen R, Johansen BK, Skare G, Haldorsen T, Eriksen T, Waage R, Molund IM: Annual Report Cervical Cancer Screening 2008. Cancer Registry of Norway 2009.

31. WHO: IARC Classification of Tumors of the Breast and Female Genital Organs, vol. Book 4. Lyon: IARCPress; 2003

32. Kruse AJ, Baak JP, de Bruin PC, Jiwa M, Snijders WP, Boodt PJ, Fons G, Houben PW, The HS: Ki-67 immunoquantitation in cervical intraepithelial neoplasia (CIN): a sensitive marker for grading. J Pathol 2001, 193(1):48-54.

33. Soreide K: Receiver-operating characteristic curve analysis in diagnostic, prognostic and predictive biomarker research. J Clin Pathol 2009, 62(1):1-5.

34. Khan MJ, Castle PE, Lorincz AT, Wacholder S, Sherman M, Scott DR, Rush BB, Glass AG, Schiffman M: The elevated 10-year risk of cervical precancer and cancer in women with human papillomavirus (HPV) type 16 or 18 and the possible utility of type-specific HPV testing in clinical practice. J Natl Cancer Inst 2005, 97(14):1072-1079.

35. Smith JS, Lindsay L, Hoots B, Keys J, Franceschi S, Winer R, Clifford GM: Human papillomavirus type distribution in invasive cervical cancer and high-grade cervical lesions: a meta-analysis update. Int J Cancer 2007, 121(3):621-632.

36. Li N, Franceschi S, Howell-Jones R, Snijders PJ, Clifford GM: Human papillomavirus type distribution in 30,848 invasive cervical cancers worldwide: Variation by geographical region, histological type and year of publication. Int J Cancer 2011, 128(4):927-935.

37. Hogewoning CJ, Bleeker MC, van den Brule AJ, Voorhorst FJ, Snijders PJ, Berkhof J, Westenend PJ, Meijer CJ: Condom use promotes regression of cervical intraepithelial neoplasia and clearance of human papillomavirus: a randomized clinical trial. Int J Cancer 2003, 107(5):811-816.

38. Rousseau MC, Franco EL, Villa LL, Sobrinho JP, Termini L, Prado JM, Rohan TE: A cumulative case-control study of risk factor profiles for oncogenic and nononcogenic cervical human papillomavirus infections. Cancer epidemiology, biomarkers \& prevention: a publication of the American Association for Cancer Research, cosponsored by the American Society of Preventive Oncology 2000, 9(5):469-476.

39. Olsen AO, Dillner J, Skrondal A, Magnus P: Combined effect of smoking and human papillomavirus type 16 infection in cervical carcinogenesis. Epidemiology 1998, 9(3):346-349.
40. McCann MF, Irwin DE, Walton LA, Hulka BS, Morton JL, Axelrad CM: Nicotine and cotinine in the cervical mucus of smokers, passive smokers, and nonsmokers. Cancer epidemiology, biomarkers \& prevention: a publication of the American Association for Cancer Research, cosponsored by the American Society of Preventive Oncology 1992, 1(2):125-129.

41. Poppe WA, Peeters R, Daenens P, Ide PS, Van Assche FA: Tobacco smoking and the uterine cervix: cotinine in blood, urine and cervical fluid. Gynecol Obstet Invest 1995, 39(2):110-114.

42. Lam TH, Stewart SM, Ho LM: Smoking and high-risk sexual behavior among young adults in Hong Kong. J Behav Med 2001, 24(5):503-518.

43. Kelly RW: Immunosuppressive mechanisms in semen: implications for contraception. Hum Reprod 1995, 10(7):1686-1693.

44. Wang X, Zhuang J, Wu K, Xu R, Li M, Lu Y: Human semen: the biological basis of sexual behaviour to promote human papillomavirus infection and cervical cancer. Med Hypotheses 2010, 74(6):1015-1016.

45. Ovestad IT, Gudlaugsson E, Skaland I, Malpica A, Munk AC, Janssen EA, Baak JP: The impact of epithelial biomarkers, local immune response and human papillomavirus genotype in the regression of cervical intraepithelial neoplasia grades 2-3. J Clin Pathol 2011, 64(4):303-307.

doi:10.1186/1750-9378-7-30

Cite this article as: Munk et al: Consistent condom use increases spontaneous regression in high-risk non-HPV16 but not in HPV16 CIN23 lesions, a prospective population-based cohort study. Infectious Agents and Cancer 2012 7:30.

\section{Submit your next manuscript to BioMed Central and take full advantage of:}

- Convenient online submission

- Thorough peer review

- No space constraints or color figure charges

- Immediate publication on acceptance

- Inclusion in PubMed, CAS, Scopus and Google Scholar

- Research which is freely available for redistribution

Submit your manuscript at www.biomedcentral.com/submit
C Biomed Central 